\title{
Leukocytes Parameters, CRP, and Ferritin in Iranian Patients with COVID-19 Infection; A Cross-sectional Study
}

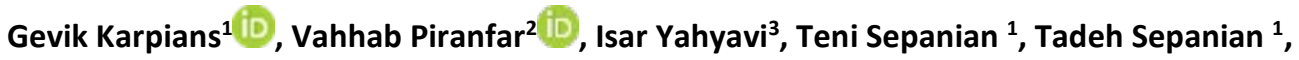 \\ Samaneh Alizadeh ${ }^{4}$, Arefeh Chandhal ${ }^{5}$
}

1. Department of Biochemistry, Medical Laboratory, Tehran, Iran

2. Research and Development Department, Farname Inc, Thornhill, Canada

3. Department of Molecular, Medical laboratory, Tehran, Iran

4. Department of Hematology, Medical Laboratory, Tehran, Iran

5. Department of Phlebotomy, Medical laboratory, Tehran, Iran

$\underline{10.30699 / i j m m .15 .3 .360}$

\section{ABSTRACT}

Background and Aim: Coronavirus disease known as COVID-19 pandemic is caused by severe acute respiratory syndrome coronavirus 2 (SARS-CoV-2), which is affecting over 200 countries all over the world. This study was aimed to identify simple and swiftly available laboratory biomarkers to help facilitate effectual triage to categorize suspected COVID-19 patients.

Materials and Methods: According to a standard protocol, we collected clinical, etiological, and laboratory data of 140 patients who underwent diagnostic tests at Medical Laboratory Group, Tehran, Iran, from October 1 to November 28, 2020, based on PCR testing for SARS-CoV-2 infection. Leukocyte parameters, C-reactive protein (CRP) and, ferritin levels were measured in patients with positive PCR COVID-19 test.

Results: 140 patients with COVID-19 infection were included in the study. The median age in women was 41.5 (23-60) years and 45.3 (22-68) years in men. Based on RT-PCR result, there were significant differences for neutrophil, lymphocyte, and monocyte counts. Overall, $72.8 \%$ of patients had monocyte count more than $11 \times 10^{9} / \mathrm{L}$. The mean neutrophil lymphocyte ratio (NLR) for women was 2.8 (SD: 1.8) and 2.6 (SD: 1.7) for men. Only in 15 patients (10.7\%) with respiratory symptoms, CRP level was more than $5 \mathrm{mg} / \mathrm{L}$.

Conclusion: We found a significant increase in monocyte count. Lymphopenia was also observed. In patients with respiratory symptoms, CRP was significantly higher than the normal reference range.

Keywords: Acute respiratory distress syndrome, Coronavirus, Cytokine release syndrome, Lymphopenia, Real Time PCR, Severe acute respiratory syndrome

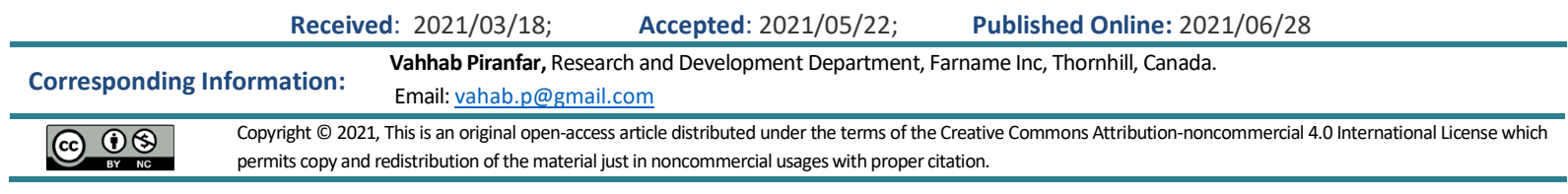

Use your device to scan and read the article online

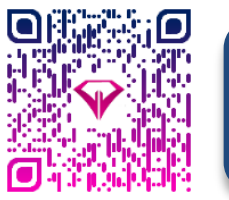

Karpians G, Piranfar V, Yahyavi I, Sepanian T, Sepanian T, Alizadeh S, Chandhal A,. Leukocytes Parameters, CRP, and Ferritin in Iranian Patients with COVID-19 Infection; A Cross-sectional Study. Iran J Med Microbiol. 2021; 15 (3) 360-367

\section{Download citation: BibTeX | RIS | EndNote | Medlars | ProCite | Reference Manager | RefWorks}
Send citation to:

\section{Mendeley}
2 Zotero

\section{HefWorks}

\section{Introduction}

Severe acute respiratory syndrome coronavirus 2 (SARS-CoV-2), which causes coronavirus disease
(COVID-19) rapidly evolved from an epidemic outbreak in China $(1,2)$ into a pandemic infecting 
people all over the world (3). COVID-19 is a virusinduced respiratory disease, which is progressed to the Acute Respiratory Distress Syndrome (ARDS), hyper inflammation, and leukocytes count variation (4). It has been testified that ACE2 is the main receptor of the host cell for the human pathogenic coronaviruses; SARS-CoV-1, MERS and SARS-CoV-2. It plays a key role in the virus entry into the cell, viral spreading and its pathogenesis $(5,6)$. Although the airways are the main locations for COVID-19 infection, the virus can distribute systemically. The epithelial and endothelial cells that express the ACE2 receptor are the major targets for viral infection (7). Nasopharyngeal epithelium is an early target for the infection and plays a role in inflammatory cytokine responses through macrophages (8). Cytokine release syndrome (CRS) is a form of systemic inflammatory reaction triggered by various factors especially infections (9). The CRS occurs when pro-inflammatory cytokines are released from large numbers of activated leucocytes (10). The IL-6 and granulocyte macrophage-colony stimulating factor (GM-CSF), which both increase during the cytokine storm in the COVID-19 patients, regulate monocyte activation $(10,11)$. The IL-6 is the leading stimulator of the most acute-phase proteins production and controls monocyte activation and differentiation (11). The GM-CSF is another cytokine related to the monocyte/macrophage activation that has an important influence under inflammatory conditions, by promoting neutrophils and monocytes proliferation, maturation, and migration (12). The GMCSF stimulates stem cells to produce monocytes and granulocytes, and promotes migration of mono-cytes to the inflammatory sites and differentiation into the inflammatory macrophages (13). The extreme activation of monocyte-macrophage may cause subsequent respiratory failure in the patients with severe respiratory infection.

Ferritin and CRP are used as early markers for infections (14) and are highly increased along with inflammatory cytokines. The essential measures to predict the mortality and severity of COVID-19 infection are clinical and laboratory biomarkers. Leukocyte changes such as neutrophilia, lymphopenia, and neutrophil-to-lymphocyte ratio (NLR) (15), could be used as predictors for the severity of COVID-19 infection. The aim of this research was to evaluate the associatiation of leukocytes, CRP, and ferritin with COVID-19 severity in the patients with positive PCR test for the COVID-19.

\section{Materials and Methods}

\section{Study Population and Laboratory Methods}

This study was conducted by Medical Laboratory Group in Tehran during the peak of COVID-19 epidemic between October 1 and November 28, 2020.
All subjects were Iranian and lived in Tehran. Suspected patients have been referred to our laboratory for Polymerase Chain Reaction (PCR) testing. Necessary information such as drug use and underlying diseases were also recorded. A nasoph-arynx sample for PCR was collected. Also, a blood sample was obtained from the cubital vein. In all tests, tubes without anti-preservative were used for the tests. After clot formation, samples were centrifuged for 15 minutes at $2500 \mathrm{rpm}$, the serum samples were separated and sent to the biochemistry section. Blood for $\mathrm{CBC}$ test was collected in EDTA K2 anticoagulant tubes. After testing daily, patients' serum was stored at $-20 \mathrm{C}$ for one week. The Cobas 6000 device, Sysmex XN 1000 Hematology inurement, real time PCR Roche were used for testing. Nasal-pharyngeal swabs and venous blood samples were examined by Medical Laboratory Group.

In this study, CRP was checked using particle enhanced turbid metric method, ferritin test with method, particle enhanced immune turbid metric assay and CBC test with flow cytometry, fluorescent technologies. Table 1 shows the information related to the normal range and test reading range. The RNA samples were extracted using Roje kit (Viga SARSCOV-2, ROJE Technologies, Iran) and subjected to realtime Revers Transcription Polymerase Chain Reaction (RT-PCR) using Pishtaz-Teb COVID-19 RT-PCR kit (Pishtaz-Teb Diagnostics, Tehran, Iran) amplyfying RdRP, and $\mathrm{N}$ genes as recommended by the manufacturer. When two genes were positive, the average of the observations was presented as representative of overall CT values; while, if only one gene was detected, the available value was used to represent the observation. According to the manufacturer instruction, the cycle threshold (CT) value $\leq 35$ was defined as positive.

Confirmation of SARS-CoV-2 was achieved by RTPCR assay in accordance with the protocol established by the WHO (World Health Organization).

Laboratory tests on admission included complete blood count, blood chemistry, and biomarkers including leucocyte, neutrophil, lymphocyte, monocyte, eosinophil, platelet, ferritin and CRP.

\section{Data Extraction}

Data was collected according to a standard protocol independently by authors from medical laboratory back up system and patient's questionnaires. In the first stage, we included only the laboratory-confirmed cases, as the diagnosis was performed by a real-time RT-PCR assay to test nasal and pharyngeal swab specimens according to the WHO guidance [16]. At this stage, 76 women and 74 men had the necessary conditions to be included. In the second stage, CBC, 
biochemistry results, and the questionnaire completed by the patient were evaluated in terms of epidemiological information. We considered patient demographic characteristics including age and gender, comorbidities such as hypertension, diabetes, cardiovascular disease, respiratory disease, blood group, clinical symptoms including fever, respiratory, and digestive symptoms. In the third stage, subjects were screened and those lacking baseline examination data $(n=10)$ were excluded. At this stage, it was determined that 70 women and 70 men had the necessary conditions to be examined. Data was analyzed in terms of various variables such as age, weight, blood group, leukocyte parameters, neutronphil lymphocyte ratio (NLR), CRP, and ferritin tests. For a comparison with healthy individuals, we collected
$\mathrm{CBC}, \mathrm{CRP}$, and Ferritin tests results from 140 healthy Iranian individual from Medical laboratory data base system.

\section{Statistical Analysis}

Determining sample size for research activities provided by Cochran ( $d=0.05)$. The Statistical Package for Social Sciences (SPSS), version 24, (SPSS Inc., Chicago, IL, USA) was used for data analysis. Descriptive statistics were performed to describe data. Categorical variables were reported through frequencies (percentages) and continuous variables were presented as a mean (SD) or median and range. For inferential statistical methods, independent t-test was conducted. The significance level was considered as $P$-value $<0.05$ in all analysis.

Table 1. Characteristics of the parameter, reference range (adult group) and methods

\begin{tabular}{|c|c|c|}
\hline Parameter & Reference Range & Methods \\
\hline 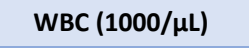 & $3.5-10.5$ & \multirow{6}{*}{ Flow cytometry, fluorescent technologies } \\
\hline Neutrophil $\left(10^{9} / \mathrm{L}\right)$ & $30-70$ & \\
\hline Lymphocyte $\left(10^{9} / \mathrm{L}\right)$ & $20-50$ & \\
\hline Monocyte $\left(10^{9} / \mathrm{L}\right)$ & $4-11$ & \\
\hline Eosinophil $\left(10^{9} / \mathrm{L}\right)$ & $0-5$ & \\
\hline Basophile (10 / L) & $<1$ & \\
\hline CRP (mg/L) & $<5$ & Particle enhanced turbid metric assay \\
\hline Ferritin (ng/mL) & $\begin{array}{l}\text { Male : } 24-330 \\
\text { Female : } 11-307\end{array}$ & Particle enhanced immune turbid metric assay \\
\hline NLR & $<4.5$ & Neutrophil lymphocyte ratio \\
\hline
\end{tabular}

\section{Results}

The mean age in women was 41.5 (23-60) years and $45.3(22-68)$ years in men. Blood groups $+O$ and $+A$ had the highest prevalence in patients. Overall, $46 \%$ of patients had blood group $+\mathrm{O}$ and $38 \%+\mathrm{A}$. The most important clinical symptoms recorded by patients in the questionnaire were general symptoms, fever and headache, respiratory symptoms such as dry cough, gastrointestinal symptoms and anosmia and ageusia. Fever and headache (46.6\% and $41.6 \%$, respectively) were the most common symptoms in patients. Meanwhile, $12 \%$ of people complained of anosmia and ageusia.

As for laboratory findings, in 15 patients (10.7\%), CRP value was more than $5 \mathrm{mg} / \mathrm{L}$. These 15 people had lung involvement and respiratory symptoms. Analysis of patients' serum ferritin data showed that only 4 patients $(2.8 \%)$ had ferritin above the normal range.

Blood parameters including white blood cell count, differential white blood cell count and neutrophil to lymphocyte ratio (NLR) were also studied in both patients and control group. According to Table 2, the mean number of white blood cell count in both men and women increased compared with the control group. White blood cell count was more than $10.5 \times 1000 / \mu \mathrm{L}$ in 19 patients (13.57\%), and only $2.8 \%$ of patients had leukopenia. Neutrophil Lymphocyte Ratio analysis for each COVID-19 patient revealed that 19.3\% had an NLR greater than 4.5 .

Besides, the mean number of monocytes in both male and female subjects of patients group was increased dramatically in comparison with control group $(P=0.04)$.

Figure 1 illustrates the abnormality of Monocyte, Neutrophil, Lymphocyte, ferritin, and CRP parameters in COVID-19 patients in this study. It was found that monocyte count was changed more than other parameters, in patients. Also, according to the bar chart, ferritin had the fewest changes. 


\begin{tabular}{|c|c|c|c|c|c|c|}
\hline \multicolumn{7}{|c|}{ Leukocytes analysis } \\
\hline \multirow{3}{*}{ Parameters } & Female $(n=70)$ & Female $(n=70)$ & \multirow{3}{*}{ P-value } & Male $(n=70)$ & male(n=70) & \multirow{3}{*}{ P-value } \\
\hline & Median (SD) & Median(SD) & & Median (SD) & Median(SD) & \\
\hline & COVID19 (+) & Control & & COVID19(+) & Control & \\
\hline $\begin{array}{c}\text { WBC } \\
(1000 / \mu \mathrm{L})\end{array}$ & $7.8(2.2)$ & 7.1(1.4) & 0.9 & $8.3(2.5)$ & $7.2(1.2)$ & 0.9 \\
\hline $\begin{array}{l}\text { Neutrophil } \\
\left(\times 10^{9} / \mathrm{L}\right)\end{array}$ & $56.6(10.4)$ & $53.3(5.4)$ & 0.4 & $55.40(10.5)$ & $51.7(4.8)$ & 0.4 \\
\hline $\begin{array}{l}\text { Lymphocyte } \\
\left(\times 10^{9} / \mathrm{L}\right)\end{array}$ & $26.3(10)$ & $37.1(4.3)$ & 0.6 & $26.8(9.0)$ & $38.4(4.5)$ & 0.8 \\
\hline NLR & $2.8(1.8)$ & $1.4(0.3)$ & 0.6 & $2.6(1.7)$ & $1.3(0.3)$ & 0.7 \\
\hline $\begin{array}{l}\text { Monocyte } \\
\left(\times 10^{9} / \mathrm{L}\right)\end{array}$ & $13.9(2.2)$ & $5.3(1.2)$ & 0.04 & $13.6(3.0)$ & $5.4(1.2)$ & 0.04 \\
\hline \multicolumn{7}{|c|}{ Acute phase protein } \\
\hline \multirow{3}{*}{ Test } & Female $(n=70)$ & Female $(n=70)$ & & Male $(n=70)$ & male $(n=70)$ & \multirow{3}{*}{ P-value } \\
\hline & Median(SD) & Median(SD) & P-value & Median (SD) & Median(SD) & \\
\hline & CoVID19(+) & Control & & CoVID19(+) & Control & \\
\hline $\begin{array}{c}\text { CRP } \\
\text { (mg/L) }\end{array}$ & $3.2(3.9)$ & $2.2(1.1)$ & 0.008 & $4.5(4.1)$ & $2.9(1.6)$ & 0.9 \\
\hline Ferritin (ng/mL) & $140(87)$ & $138(81)$ & 4.0 & $168(72)$ & $157(61)$ & 0.6 \\
\hline
\end{tabular}

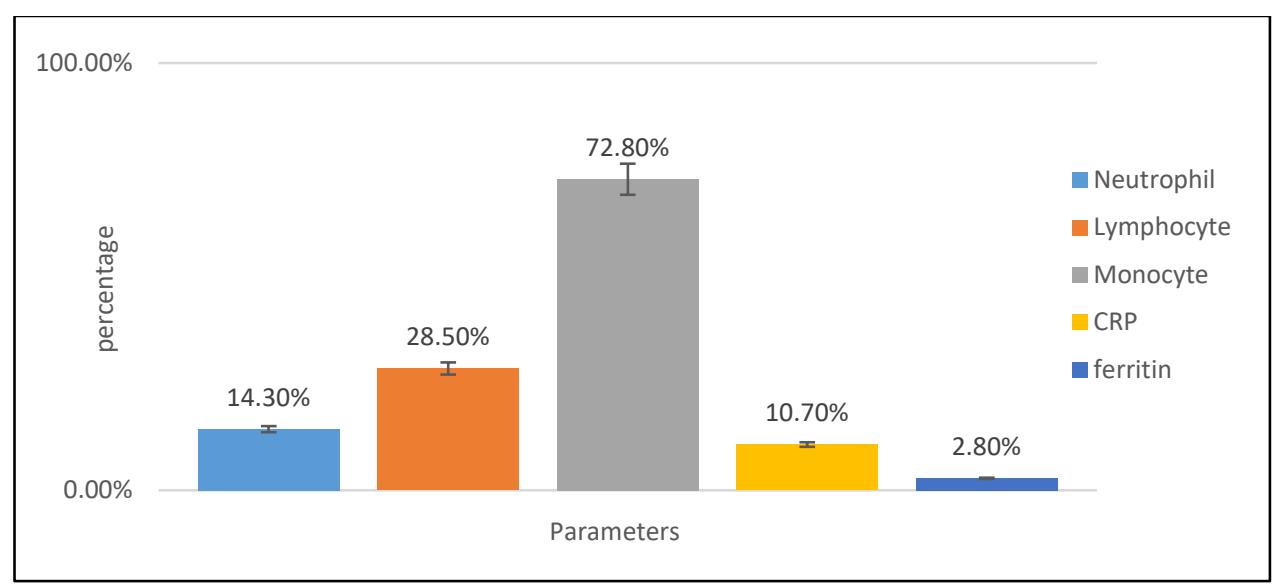

Figure 1. Percentage of abnormality of Monocyte, Neutrophil, Lymphocyte, ferritin, and CRP parameters in COVID-19 patients in this study.

\section{Discussion}

The number of COVID-19 patients is increasing globally, and asymptomatic patients are one of the main sources of infection spread (17-19). Different biomarkers such as CRP and ferritin have been recognized for this disease severity (20). CRP which is correlated with the level of inflammation can be served as an early marker of infection $(21,22)$. It is an acute-phase protein and its concentration level is not affected by the factors such as sex, age, and physical condition (23). CRP levels can be used for the early diagnosis of pneumonia, and the patients with severe pneumonia have shown high levels of CRP [24]. Our study findings were consistent with the recent public- cations (24-26), which showed that the CRP level on admission was a sensitive and early indicator for the COVID-19 severity. Our results highlighted that $10.7 \%$ of the patients had CRP levels higher than $5 \mathrm{mg} / \mathrm{L}$ and they had respiratory involvement. CRP levels were positively correlated with the lung lesion and disease severity (27). This suggests that, CRP level could be used as an indicator of disease severity in the early stage of COVID-19.

In our study, only $2.80 \%$ of patients had higher ferritin levels than the normal reference range. In studies on ferritin levels in COVID-19 patients, only in patients with acute conditions, ferritin levels were very high. In 
one study with twenty COVID-19 patients, it was found that individuals with severe and very severe COVID-19 infection exhibited increased serum ferritin level (28). Chen et al. analyzed the clinical characteristics of 99 patients and reported that 63 of them had serum ferritin levels above the normal range (29).

One of the main specifications of ARDS is cytokine storm, which is a lethal excessive systemic inflammatory response, caused by the production of high levels of pro-inflammatory cytokines, such as TNF $\alpha$, IL6, IFN $\alpha$, IL1 $\beta$, IFN $\gamma$, IL18 and IL12 (30).

The COVID-19 patients have shown the lowest and te highest counts of lymphocytes and neutrophils, respectively (25). Several studies have confirmed that increased pro-inflammatory cytokines and dysregulation of the immune response may play a critical role in lymphopenia induction, which is one of the hallmarks of severe SARS-CoV-2 infection (31).

In this study it was found that the average number of neutrophils in patients with COVID-19 was increased. Among them, $14.30 \%$ had neutrophil counts higher than $70 \times 10^{9}$, while the average number of lymphocytes in these patients decreased and $28.5 \%$ of patients had a lymphocyte count less than $20 \times 10^{9}$. As in other studies, an increase in neutrophils and a decrease in lymphocytes have been observed in patients with COVID-19.

Neutrophil-to-lymphocyte ratio (NLR) is a simple and good marker to assess the inflammatory status (15). A number of studies have stated that NLR, which is a clinical inflammation biomarker is augmented which is predictive of severe illness in the early stage of SARS-CoV-2 infection (32). Wang et al. also showed that several patients with COVID-19 infection have a rising neutrophil count and a falling lymphocyte count during severe phase of this infection (33). Overall, in our study $19.3 \%$ of patients had higher NLR than normal reference range.

In the present study, based on the analysis of monocytes results, we found significant increases in monocytes count in COVID-19 patients. According to the results the average number of monocytes increased and $78.4 \%$ of them had monocyte counts higher than normal reference interval range $11 \times 10^{9}$. Our findings were consistent with the recent publications, which indicated that monocyte may be a sensitive marker for rapid triage of patients suspected to COVID-19 infection (34). Monocytes and macrophages play significant role in operating early inflammatory reactionsby the innate immune system (35). Zhang et al., provided important data highlighting the potential contribution of monocytes to the viral cytokine storm during SARS-COV-2 infection. They also suggested a possible role of shifts in the monocyte subpopulations in mediating severity of the disease (36).

\section{Conclusion}

COVID-19 is a respiratory disease induced by SARSCOV-2 virus and may progress to ARDS, hyper inflammation, and leukocytes count changes. White blood cells and acute phase proteins provide a window on the systemic immune response. In the present study, based on the analysis obtained from 140 Iranian patients with COVID-19 we analyzed biochemistry parameters and white blood cell count in COVID-19 positive patients. The purpose of this study was to evaluate acute phase proteins and white blood cells according to routine tests. We found significant increases in monocyte count, meanwhile lymphopenia was observed in patients. Besides, in patients with respiratory symptoms, CRP was significantly higher than normal reference range.

\section{Acknowledgment}

The authors would like to thank Mr. Ahmad Omran the management of medical laboratory Group for his kindly efforts.

\section{Conflict of Interest}

The authors declare no conflict of interest.

2020;28(130):253-64

[DOI:10.30699/jambs.28.130.253]

3. Jalali Nadoushan M, Ahmadi S, Jalali Nadoushan P. Serology Testing for SARS-CoV-2: Benefits and Challenges. Iran J Pathol. 2020;15(3):154-5. [DOI:10.30699/ijp.2020.39841]

4. Mehta P, McAuley DF, Brown M, Sanchez E, Tattersall RS, Manson JJ. COVID-19: consider cytokine storm syndromes and 
immunosuppression.

The

Lancet

2020;395(10229):1033-4. [DOI:10.1016/S0140-

6736(20)30628-0]

5. Wu Z, McGoogan JM. Characteristics of and Important Lessons From the Coronavirus Disease 2019 (COVID-19) Outbreak in China: Summary of a Report of 72314 Cases From the Chinese Center for Disease Control and Prevention. JAMA. 2020;323(13):1239-42. [DOI:10.1001/jama.2020.2648]

6. Mirsadraee $S$, Pourabdollah Toutkaboni $M$, Bakhshayeshkaram M, Rezaei Ms, Askari E, Haseli S, et al. Radiological and Laboratory Findings of Patients with COVID-19 Infection at the Time of Admission. Iran J Pathol. 2020;16(2):137-43. [DOI:10.30699/ijp.2020.128909.2415]

7. Madjid M, Safavi-Naeini P, Solomon SD, Vardeny O. Potential Effects of Coronaviruses on the Cardiovascular System: A Review. JAMA Cardiol. 2020;5(7):831-40.

[DOI:10.1001/jamacardio.2020.1286]

8. Tang N, Li D, Wang X, Sun Z. Abnormal coagulation parameters are associated with poor prognosis in patients with novel coronavirus pneumonia. J Thromb Haemost. 2020;18(4):844-7. [DOI:10.1111/jth.14768]

9. Tkacova R. Systemic inflammation in chronic obstructive pulmonary disease: may adipose tissue play a role? Review of the literature and future perspectives. Mediators Inflamm. 2010;2010:585989. [DOI:10.1155/2010/585989]

10. Costela-Ruiz VJ, Illescas-Montes R, Puerta-Puerta JM, Ruiz C, Melguizo-Rodríguez L. SARS-CoV-2 infection: The role of cytokines in COVID-19 disease. Cytokine Growth Factor Rev. 2020;54:62-75. [DOI:10.1016/i.cytogfr.2020.06.001]

11. Hadjadj J, Yatim N, Barnabei L, Corneau A, Boussier $\mathrm{J}$, Smith $\mathrm{N}$, et al. Impaired type I interferon activity and inflammatory responses in severe COVID-19 patients. Science. 2020;369(6504):718-24. [DOI:10.1126/science.abc6027]

12. Kim WK, McGary CM, Holder GE, Filipowicz AR, Kim $M M$, Beydoun $H A$, et al. Increased Expression of CD169 on Blood Monocytes and Its Regulation by Virus and CD8 T Cells in Macaque Models of HIV Infection and AIDS. AIDS Res Hum Retroviruses. 2015;31(7):696-706. [DOI:10.1089/aid.2015.0003]

13. Bourgoin $P$, Lediagon $G$, Arnoux I, Bernot $D$, Morange $P E$, Michelet $P$, et al. Flow cytometry evaluation of infection-related biomarkers in febrile subjects in the emergency department. Future Microbiol. 2020;15:189-201. [DOI:10.2217/fmb2019-0256]
14. Sharma V, Bryant C, Montero M, Creegan M, Slike B, Krebs SJ, et al. Monocyte and CD4+ T-cell antiviral and innate responses associated with HIV-1 inflammation and cognitive impairment. Aids. 2020;34(9):1289-301.

[DOI:10.1097/QAD.0000000000002537]

15. Conti P, Younes A. Coronavirus COV-19/SARS-CoV-2 affects women less than men: clinical response to viral infection. J Biol Regul Homeost Agents. 2020;34(2):339-43.

16. Ural BB, Yeung ST, Damani-Yokota P, Devlin JC, de Vries $M$, Vera-Licona $P$, et al. Identification of a nerve-associated, lung-resident interstitial macrophage subset with distinct localization and immunoregulatory properties. Sci Immunol. 2020;5(45):eaax8756.

[DOI:10.1126/sciimmunol.aax8756]

17. Tuaillon E, Bolloré K, Pisoni A, Debiesse S, Renault C, Marie S, et al. Detection of SARS-CoV-2 antibodies using commercial assays and seroconversion patterns in hospitalized patients. J Infect. 2020;81(2):e39-e45.

[DOI:10.1016/j.jinf.2020.05.077]

18. Chevrier S, Zurbuchen Y, Cervia C, Adamo S, Raeber $\mathrm{ME}$, de Souza $N$, et al. A distinct innate immune signature marks progression from mild to severe COVID-19. Cell Rep Med. 2021;2(1):100166. [DOI:10.1016/j.xcrm.2020.100166]

19. Michel M, Malergue F, Belkacem IA, Bourgoin $P$, Morange P-E, Arnoux I, et al. An ultra-sensitive, ultra-fast whole blood monocyte CD169 assay for COVID-19 screening. medRxiv. 2020:2020.10.22.20215749. [DOI:10.1101/2020.10.22.20215749]

20. Michlmayr D, Kim E-Y, Rahman AH, Raghunathan R, Kim-Schulze $S$, Che $Y$, et al. Comprehensive Immunoprofiling of Pediatric Zika Reveals Key Role for Monocytes in the Acute Phase and No Effect of Prior Dengue Virus Infection. Cell Rep. 2020;31(4):107569.

[DOI:10.1016/j.celrep.2020.107569]

21. Raesi A, Saedi Dezaki E, Moosapour H, Saeidifard F, Habibi Z, Rahmani F, et al. Hypocalcemia in COVID19: A Prognostic Marker for Severe Disease. Iran J Pathol. 2020;16(2):144-53.

[DOI:10.30699/ijp.2020.130491.2442]

22. Sproston NR, Ashworth JJ. Role of C-Reactive Protein at Sites of Inflammation and Infection. Front Immunol. 2018;9:754-. [DOI:10.3389/fimmu.2018.00754]

23. Bourgoin $P$, Soliveres $T$, Barbaresi $A$, Loundou $A$, Belkacem IA, Arnoux I, et al. CD169 and CD64 could help differentiate bacterial from COVID-19 or other 
viral infections in the Emergency Department. Cytometry A. 2021;99(5):435-45. [DOI:10.1002/cyto.a.24314]

24. Gewurz H, Mold C, Siegel J, Fiedel B. C-reactive protein and the acute phase response. Adv Intern Med.

1982;27:345-72.

[DOI:10.1080/21548331.1982.11702332]

25. Ahnach M, Zbiri S, Nejjari S, Ousti F, Elkettani C. Creactive protein as an early predictor of COVID-19 severity. J Med Biochem. 2020;39(4):500-7. [DOI:10.5937/jomb0-27554]

26. Wang L. C-reactive protein levels in the early stage of COVID-19. Méd Mal Infect. 2020;50(4):332-4. [DOl:10.1016/i.medmal.2020.03.007]

27. Chalmers S, Khawaja A, Wieruszewski PM, Gajic O, Odeyemi Y. Diagnosis and treatment of acute pulmonary inflammation in critically ill patients: The role of inflammatory biomarkers. World J Critic Care Med. 2019;8(5):59-71.

[DOI:10.5492/wjccm.v8.i5.74]

28. Chen W, Zheng KI, Liu S, Yan Z, Xu C, Qiao Z. Plasma CRP level is positively associated with the severity of COVID-19. Ann Clin Microbiol Antimicrob. 2020;19(1):18. [DOI:10.1186/s12941-020-00362-2]

29. Wang G, Wu C, Zhang Q, Wu F, Yu B, Lv J, et al. CReactive Protein Level May Predict the Risk of COVID-19 Aggravation. Open Forum Infect Dis. 2020;7(5). [DOI:10.1093/ofid/ofaa153]

30. Tan C, Huang Y, Shi F, Tan K, Ma Q, Chen Y, et al. Creactive protein correlates with computed tomographic findings and predicts severe COVID-19 early. J Med Virol. 2020;92(7):856-62. [DOI:10.1002/jmv.25871]
31. Culebras E, Hernández F. ACE2 is on the $X$ chromosome: could this explain COVID-19 gender differences? Eur Heart J. 2020;41(32):3095-. [DOI:10.1093/eurheartj/ehaa521]

32. Dexamethasone in Hospitalized Patients with COVID-19. New England Journal of Medicine. 2020;384(8):693-704.

[DOI:10.1056/NEJMoa2021436]

33. Gianfrancesco M, Hyrich KL, Al-Adely S, Carmona L, Danila MI, Gossec L, et al. Characteristics associated with hospitalisation for COVID-19 in people with rheumatic disease: data from the COVID-19 Global Rheumatology Alliance physician-reported registry. Ann Rheum Dis. 2020;79(7):859-66. [DOI:10.1136/annrheumdis-2020-217871]

34. Channappanavar R, Perlman S. Evaluation of Activation and Inflammatory Activity of Myeloid Cells During Pathogenic Human Coronavirus Infection. Methods Mol Biol. 2020;2099:195-204. [DOI:10.1007/978-1-0716-0211-9 15]

35. Conti $P$, Gallenga CE, Tetè G, Caraffa A, Ronconi G, Younes $A$, et al. How to reduce the likelihood of coronavirus-19 (CoV-19 or SARS-CoV-2) infection and lung inflammation mediated by IL-1. J Biol Regul Homeost Agents. 2020;34(2):333-8.

36. Zhang D, Guo R, Lei L, Liu H, Wang Y, Wang Y, et al. Frontline Science: COVID-19 infection induces readily detectable morphologic and inflammationrelated phenotypic changes in peripheral blood monocytes. J Leukoc Biol. 2021;109(1):13-22. [DOI:10.1002/JLB.4HI0720-470R] 


\title{
پارامترهاى لكوسيتها، CRP و فريتين در بيماران ايرانى مبتلا به عفونت COVID-19
} يك مطالعُء مقطعى دو بيمان اير

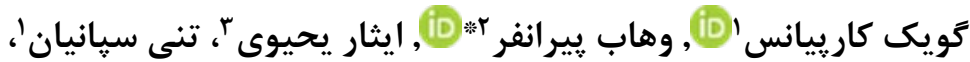

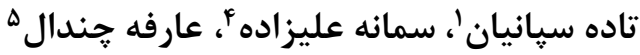

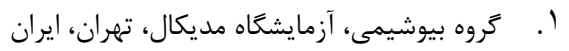

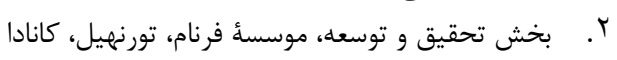

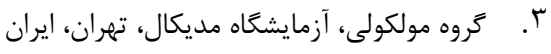

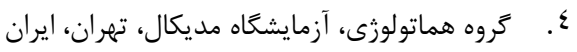

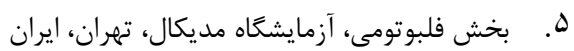

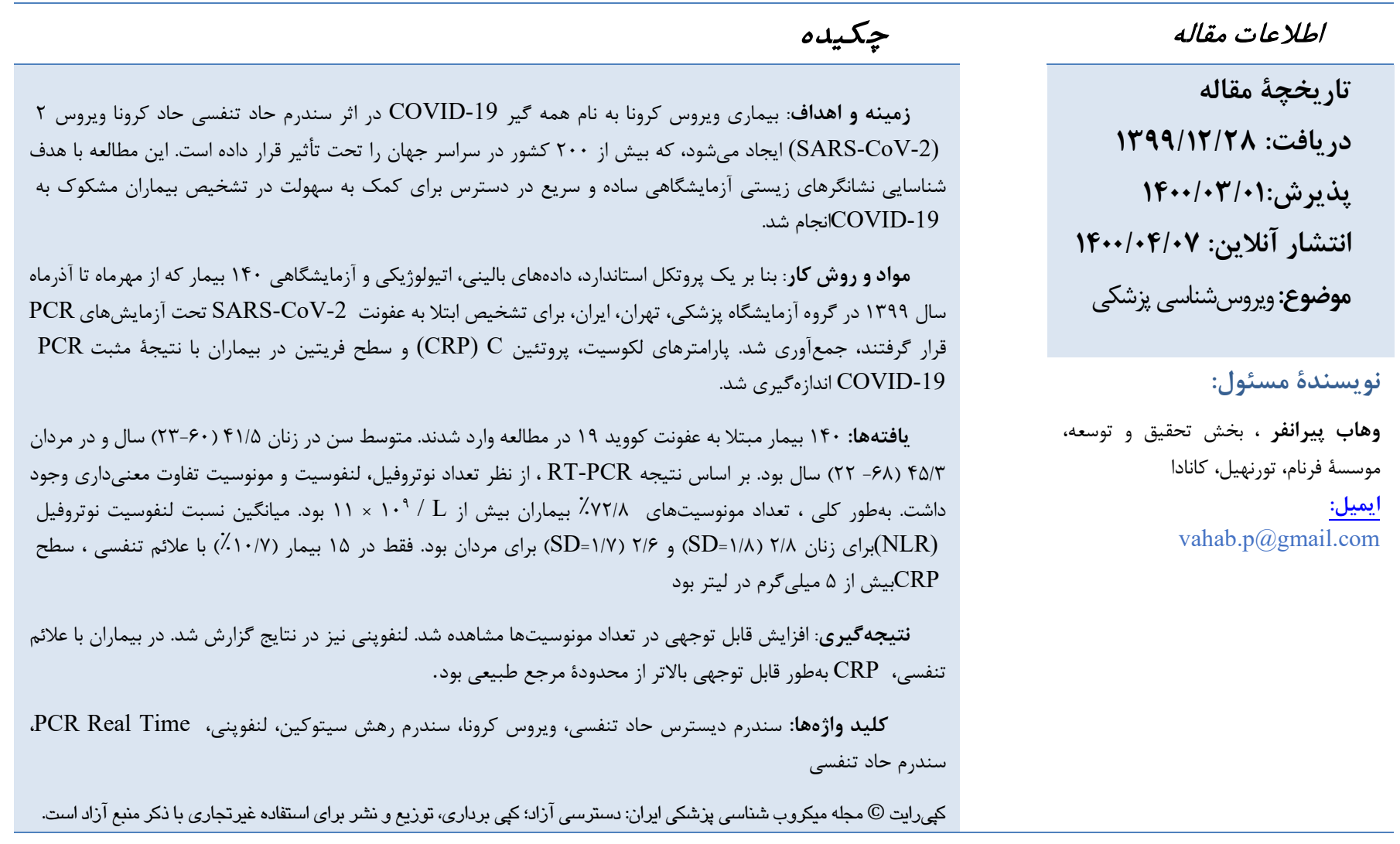

